\title{
Lower Back Pain Among Neurological and Neurosurgical Adult Patients at an Armed Forces Hospital Addis Ababa, Ethiopia
}

\author{
Shewalem Geremew Denboba ${ }^{1,}$, , Alemayehu Worku² \\ ${ }^{1}$ Department of Internal Medicine, Zewditu Memorial Hospital, Addis Ababa, Ethiopia \\ ${ }^{2}$ Department of Biostatics, Schools of Public Health, Addis Ababa Universities and Addis Continental Institute of Public Health, Addis \\ Ababa, Ethiopia
}

Email address:

shewalemg@yahoo.com (S. G. Denboba)

${ }^{*}$ Corresponding author

\section{To cite this article:}

Shewalem Geremew Denboba, Alemayehu Worku. Lower Back Pain Among Neurological and Neurosurgical Adult Patients at an Armed Forces Hospital Addis Ababa, Ethiopia. American Journal of Internal Medicine. Vol. 9, No. 3, 2021, pp. 127-137.

doi: 10.11648/j.ajim.20210903.14

Received: March 5, 2021; Accepted: May 21, 2021; Published: May 27, 2021

\begin{abstract}
Lower back pain differs in prevalence with respect to gender, time, occupation and nations and little is known about it on military professionals in Ethiopia who are exposed to more workload, psychological disorders and regular physical exercise hence we aimed in this study to assess the magnitude of lower back pain and its determinants among neurological and neurosurgical adult patients at Armed Forces Comprehensive Specialized Hospital Addis Ababa, Ethiopia from December 16, 2017 to March 23, 2018. For this aim a comparative crossectional study was carried out, and using single and two population proportion formulas, sample size of 585 was calculated. Every third participants aged more than or equal to 18 years were included in the study. Descriptive statics and bivariate and multivariable logistic regression was done for variables. The study results showed response rate of the study is $99.7 \%$ and the median age is 42 years with interquartile range of 14 years, 447 (76.7\%) of them are male and $441(75.6 \%)$ are military. The magnitude of low back pain is $65.9 \%$ with $95 \%$ Confidence Interval $(62.1,69.8)$; and previous recommended spinal surgery, tender point, comorbidities, and numbness and tingling sensation have significant association in multivariable logistic regression with adjusted odds ratio (95\% Confidence Interval) $2.18(1.06,4.45), 4.36(2.17,8.77), 0.57(0.35,0.95)$, and $2.92(1.71,4.96)$; respectively. Finally, we concluded that the magnitude of lower back pain is high neurological and neurosurgical adult military patients at study settings and determinants are recommended spinal surgery, and numbness and tingling sensation, tender point and comorbidities; and strengthening neurological and neurosurgical services are recommended.
\end{abstract}

Keywords: Lower Back Pain, Determinants, Military, Ethiopia

\section{Introduction}

\subsection{Background}

Lower back pain (LBP) is a common disorder involving the muscles, nerves, and bones of the back and the term lower and low back pain is used interchangeably [1]. It was the leading global cause of disability in 2015 in most countries [2]. It differs in prevalence with respect to, gender [3-7], occupation [8-12] and nations [6, 13-16].

It has multiple risk factors that are classified as non- modifiable and modifiable $[17,18]$. Non -modifiable risk factors include age, gender, previous LBP, marital status, and education level while modifiable risk factors are obesity [3, 9, 19-21], low income, psychological disorders like depression, posttraumatic stress disorder and anxiety disorder; moderate to vigorous physical activity $[3,12,15$, 22, 23]; stress [6, 15]; parental social class, self -perceived health,, societal attitudes \& beliefs, social networks and social class $(17,18)$; work load [7, 12, 13, 24]; smoking; falls; and working shift, physical activities at work; sleep disturbance, felt little pleasure by doing things and job 
satisfaction [15]. The modifiable risk factors are amenable to preventive strategies to reduce the morbidity of LBP as LBP is among the top ten causes of Year lost due to disability (YLD) in all country including Ethiopia [25].

Besides large international variation in the prevalence of lower back pain among occupational groups carrying out similar tasks which is only partially explained by the personal and socioeconomic factors [17].

\subsection{The Magnitude of Lower Back Pain}

A study in school teachers in Gonder town, North Ethiopia, 2013 revealed of 602 teachers, $346(57.5 \%)$ experienced LBP throughout their job career, and the twelve month prevalence of LBP among teachers was 324 (53.8\%) [8]. Overall annual prevalence of self-reported work related musculoskeletal disorders in a study on nurses in Gonder governmental health institution on 2015 was 57.1\% [21]. A study in Adama hospital Medical College staff in 2015 revealed that point prevalence, annual prevalence and life time prevalence were $28.9 \%, 41.4 \%$ and 50.6\%, respectively [12]. A study on 395 nurse in Black Lion Hospital (BLH) in Addis Ababa, 2016 showed the point prevalence of low back pain $179(45.3 \%)$ while the prevalence of LBP in the previous 12-months was 181 (45.8\%), 95\% CI (40.8\%-50.6\%) [15].

The study in Addis Ababa, Ethiopia revealed that the level of awareness of occupational hazards among welders was high (86.5\%). However, this does not mean that there will be no need for further strengthening of the safety measures as significant proportions of the workers still had low awareness [26].

\subsection{Risk Factors of Lower Back Pain}

Risk factors of LBP include age, occupation, female gender [4-7], marital status, low income, low education level, comorbidity, job satisfaction, smoking [7, 16], psychological disorders (e. g. anxiety or depression), obesity $[9,19,21]$, moderate or vigorous physical exercise $[12,16$, $19,22,23]$, work load, history of low back pain, and injuries. Besides, LBP is affected by working shift, physical activities at work; sleep disturbance and felt little pleasure by doing things [15].

\subsection{The Rationale for the Study}

Despite few studies on LBP prevalence and determinants in Ethiopia on different group of professionals (teachers, nurses and pedestrian back loading women) $[3,8,12,15,21]$, little is known about lower back pain on military professionals who are exposed to more workload, psychological disorders and moderate to vigorous physical exercises, frequent accidental falls etc. Moreover, interventions to boost workers awareness of occupational hazards should focus on areas, such as provision of safety trainings, promotion of safety advocacy, and enforcement of appropriate workplace safety regulation [26].

Therefore, knowing the magnitude of LBP and its determinants will help to plan for appropriate interventions as the return to work (RTW) after experiencing LBP is mandatory to attain better mission in military activities and RTW is also influenced by different factors like managerial knowledge, attitude and behavior [27]. Hence we aimed in this study to assess the magnitude of lower back pain and its determinants among neurological \& neurosurgical adult patients at Armed Forces Comprehensive Specialized Hospital (AFCSH) Addis Ababa, Ethiopia from December 16, 2017 to March 23, 2018.

\section{Methods}

\subsection{Study Settings}

Armed Forces Comprehensive Specialized Hospital is located in Addis Ababa, Ethiopia; it is a military institution of the country where all the military personnel and their family from the whole country and hospital staffs get health services. Besides, it is a central military hospital which gets patients from Minister of Defense organization in Addis Ababa and referral from four command hospital and multiple hospitals around Addis Ababa that are in military camps.

Most of diagnostic materials are present in this military hospital which include X-ray, magnetic resonance imaging (MRI), computed tomography (CT) scan, laboratory services, electrocardiography, echocardiography, endoscopy; and outpatient and in-patient services for all major medical disciplines like surgery, medicine, gynecology /obstetrics and pediatrics; subspecialty neurology and orthopedics services. In all days of the week except Friday and Sunday neurology outpatient services are carried out by three neurologists (two full- timers and one part-timer) and neurosurgery outpatient service is carried out weekly every Friday by par-timer neurosurgeon. At neurology and neurosurgery specialty clinic those patients get neuroimaging as required. Moreover, there are four local and one Chinese radiologist who report the imaging of those patients except CT scan report which is reported by private radiologist.

\subsection{Study Design}

Cross-sectional study design with internal comparison was used in this study.

\subsection{Source Population}

All patients who are more than equal to 18 years of age and presented to general outpatient departments (OPDs) and specialty referral OPDs to Armed Forces Comprehensive Specialized Hospital Addis Ababa, Ethiopia.

\subsection{Study Population}

All neurological and neurosurgical patients who presented for neurological disorders to Armed Forces Comprehensive Specialized Hospital Addis Ababa, Ethiopia from December 16, 2017 to March 23, 2018.

\subsection{Exclusion Criteria}

Those sampled patients who did not give verbal consent to 
be included or those who want to withdraw.

\subsection{Inclusion Criteria}

All neurological and neurosurgical patients who are more than equal to 18 years of age and gave verbal consent who presented for neurological and neurosurgical disorders to Armed Forces Comprehensive Specialized Hospital Addis Ababa, Ethiopia from December 16, 2017 to March 23, 2018.

\subsection{Sample Size and Sampling Procedure}

Epi Info Version 7 was used to calculate the sample size of this study and as sample estimated for point prevalence using single population proportion is greater than that for significant determinants of LBP using two population proportions formulas that is 548 . But we took 585 for sample size for this study as the numbers of smoker were not enough with the sample size of 548.

Technical feasibility study was done during proposal preparation and allocation of 39 patients with the case in five days per week was found though one OPD day of the week was missed by one of the neurologist. As it was seen in technical visibility period assessment which was done on charts after verbal permission had gotten from the director of the hospital.

Sampling procedure was carried out by taking every 3rd patients (using systematic random sampling) since 20 to 25 patients were visiting neurology and neurosurgery OPDs on daily basis for six days a week from Monday to Saturday in the study setting from December 16, 2017 to March 23, 2018. During the last week of the study period same sampling procedure was done but only new patients who came for first time to neurological and neurosurgical referral clinic was sampled and included in the study. This is to avoid duplication of sampling as it was already 3 months and patients came for appointments.

\subsection{Data Collection Tools and Procedures}

Dr. Mark Valente's Disc spine Institute LBP Questionnaire was used for clinical variables of LBP [28], and the other most important variables in relation to LBP were extracted from different literatures reviewed. The data collection tool was translated to Amharic language for data collection and retranslated back to English for data entry. Thirty (5\% of sample size) questionaries' were tested from December 13 to 15, 2017 and completeness and clarity were checked. The purpose of the questionnaire pretest was to assess the applicability of the questionnaire, and hence correction was done for current working status, third choice not applicable was added; others (specify) was added for third choice of source of referral; fourth choice, not applicable added for duration of lower back pain; history of depression was omitted for vague meaning; have you attempted other forms of pain management was modified as specify rather than yes /no alternatives of different forms of management as they were not pertinent to the clients.

Pretested structured questionnaires were implemented for sociodemographic variables, clinical and radiological variables and dependent variable.

Data collection had been carried out in Amharic language by two data collectors who are BSc nurses age 50 years old male with 30 years of nursing experience and four time experiences of data collection, and the second one 28 years old female nurse with 8 years experiences of nursing. It was possible to collect the data by single collector a day and agreed to pay 20 birr per questionnaire. Both were trained and supervised by principal investigator. As patients are referred to neurology and neurosurgery specialty clinics from six general regular medical OPDs and other specialty referral OPDs, other than neurological and neurosurgical referral OPDS, after screening for neurological and neurosurgical disorders. The data collectors filled the questionnaire by doing all necessary history for most variables and physical examination for tender point and weight and height measurement. Besides radiologists' report was taken as it was documented at the conclusion.

\subsection{Operational Definitions}

Lower back pain: self - reported pain at the lower back

(near the midline in the lumbar or sacral region that is from the level of the lowest rib down to the gluteal fold), with or without radiation into the legs [29] and spinal imaging with or without risk factor/s.

Non -specific lower back pain: when there is no clear causal relationship between the symptoms, physical findings, and imaging findings [29].

Determinants of lower back pain: risk factors for LBP that are mentioned in the literature reviewed.

Spinal imaging: L/S x-ray or CT scan or MRI.

BMI: weight in kilograms divided by the square of the height in metres $\left(\mathrm{kg} / \mathrm{m}^{2}\right)$. If your BMI is less than 18.5 , underweight; 18.5 to $<25$, normal; 25.0 to $<30$, overweight range; 30.0 or higher, it falls within the obese range [30].

\subsection{Data Management and Analysis}

Data quality assurance was done by check in on weekly bases on completeness because the imaging result were found on next visit and data was entered to Epi-info 7 and exported to SPSS Version 20 for analysis. The categorical variable was dichotomized as yes and no, and assigned 1 for yes and 0 for no. The data was cleaned from encryption and logical error. Data cleaning was done by editing after data entry and frequencies of variables were calculated to check for missing values. The collected data was stored in a locked drawer; data files were saved in personal Laptop and both was not allowed to be used by other person except the advisor and ACIPH.

The data analysis included calculating descriptive statistics for sociodemographic, clinical and radiological variables, and odds ratio, adjusted odds ratio, 95\% confidence interval, Pvalue less than or equal to 0.05 for significance. Median and interquartile range was calculated for continuous variables. We computed each imaging types using multiple steps at 
transform and compute variable commands on SPSS. We analyzed specific LBP on bootstrap for the magnitude with 95\% CI.

Logistic regressions for bivariate and multivariable analysis of categorical and numerical variables were done for determinants of LBP to check for association with the dependent variable. To accommodate all possible risk factors, those with P-value less than or equal to 0.1 on bivariate logistic analysis were included in multivariable logistic model. Hosmer and Lemeshow Test, and Nagelkerke R square were checked. Types of weakness experienced and duration of pain were restricted during analysis.

\section{Ethical Consideration}

Ethical clearance was taken from ACIPH ERB on date December 01, 2017 and reference number ACIPH $\mathrm{MPH} / 018 / 10$, and permission based on ACIPH ethical approval had gotten from AFCSH. Verbal consent was taken from individual participants. Confidentiality was maintained by removing all identifiers of individuals like telephone numbers and names, and coding of the questionnaire and just using the information only by investigators and not sharing them to others.

\section{Results}

The response rate of the study population was $99.7 \%$. The median age of the study population is 42 years with interquartile range (IQR) of 14 years and 447 (76.7\%) of the study populations are male. Military respondents comprise $441(75.6 \%)$ of the study population while $142(24.4 \%)$ are civilians. Five hundred fifty seven (99\%), 421 (72.2\%), \& $460(78.9 \%)$ of the study population are educated, married, and orthodox by religion, respectively (Table 1).

Sixty four $(11 \%)$ of the study populations are smoking cigarette, $251(43.1 \%)$ have got provision of working office, $292(50.1 \%)$ sitting more than 6 hours in a day and 290 (49.7\%) work more than 48 hours per week (Table 2).

Among respondents to whom L/S x-ray were done, degenerative changes on L/S x-ray were found in 137 (23.5\%) of them; of those to whom L/S CT Scans were done, 24 (4.1\%) of them had degenerative and / or disc buldge or prolapse; and of those to whom L/S MRI were done, 309 (53\%) had degenerative and / or disc buldge or prolapse. Hence abnormal L/S imaging was found in 384 (65.9) of respondents (add up of the 3 imaging types). Moreover, we had symptoms of LBP in 469 respondents in this study. Specific LBP was computed on the SPSS by using 469 LBP symptoms and 384 abnormal L/S imaging and hence we got 363 respondents with specific LBP, and when we added up leg pain we found $384(65.9 \%)$ of the respondents had specific LBP.

The magnitude of patients with LBP among neurological and neurosurgical adult patients at AFCSH from December 16, 2017 to March 23, 2018 is $65.9 \%$ with 95\% CI (62.1,
69.8).

Table 1. Sociodemographic characteristics of respondents among neurological and neurosurgical adult patients at Armed Forces Comprehensive Specialized Hospital from December 16, 2017 to March 23, $2018(n=583)$.

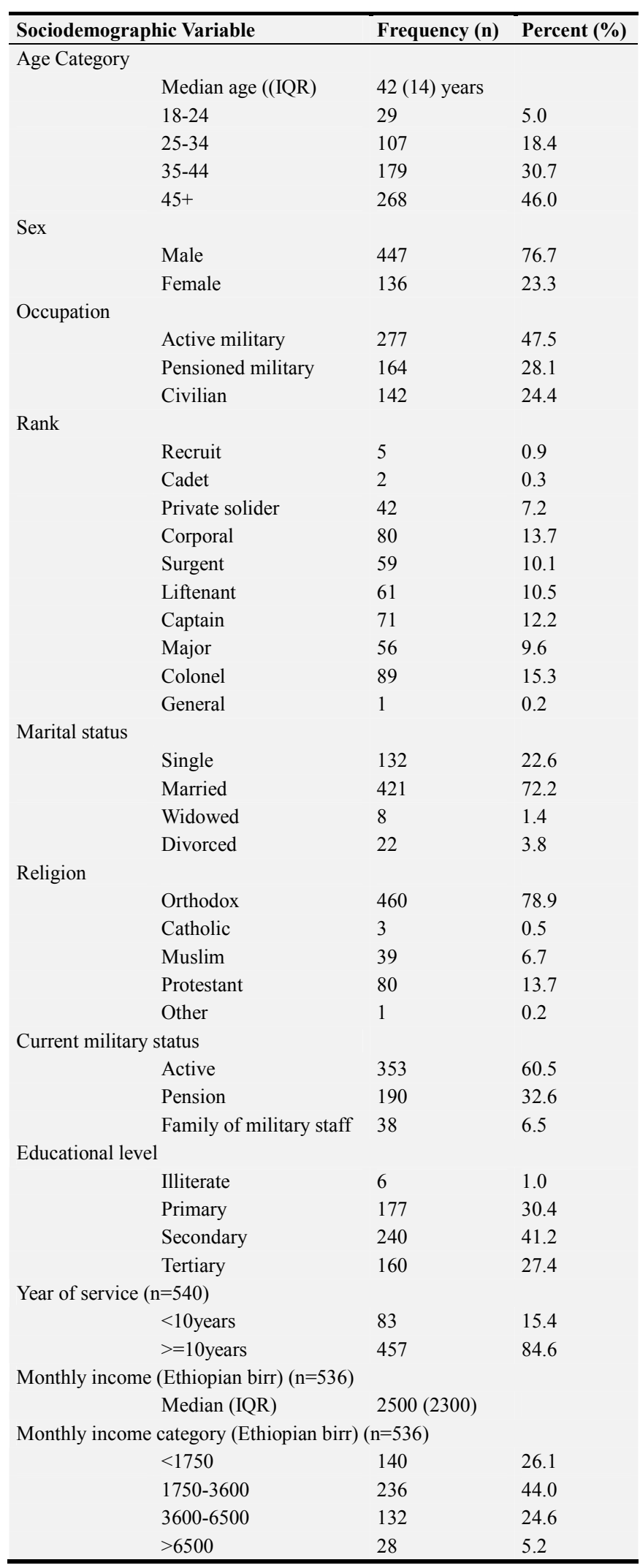


Numbness and tingling sensation are present $415(71.2 \%)$ while weakness of legs in 165 (28.3\%) of respondents. Spinal surgery was recommended and performed in 122 (20.9\%) and $15(2.6 \%)$ of the study populations, respectively. Non surgical pain treatments have gotten in $534(91.6 \%)$ of respondents and these include non- steroidal antiinflammatory drugs (NSAIDs) 339 (58.1\%), opiate (tramadol)
155 (26.6\%), tricyclic antidepressant (amitriptyline) 64 (11\%), Paracetamol 25 (4.3\%), physiotherapy $3(0.5 \%)$, and others including neurobin (2) and unspecified medication 22 (3.8\%). In $106(18.2 \%)$, there is past LBP; accidental fall is found in $343(58.8 \%)$ and history of lifting more than or equal to $25 \mathrm{kgs}$ objects in $461(79.1 \%)$ of respondents (Table 3).

Table 2. Lifestyle characteristics of respondents among neurological and neurosurgical adult patients at Armed Forces Comprehensive Specialized Hospital from December 16, 2017 to March 23, 2018.

\begin{tabular}{|c|c|c|c|}
\hline \multicolumn{2}{|l|}{ Lifestyle Variable } & Frequency (n) & Percent (\%) \\
\hline \multicolumn{4}{|c|}{ Working place office provided $(\mathrm{n}=583)$} \\
\hline & No & 332 & 56.9 \\
\hline & Yes & 251 & 43.1 \\
\hline \multicolumn{4}{|c|}{ Prolonged sitting (more than 6 hours) $(n=583)$} \\
\hline & No & 291 & 49.9 \\
\hline & Yes & 292 & 50.1 \\
\hline \multicolumn{4}{|c|}{ Working more than 48 hours per week ( $=583$ ) } \\
\hline & No & 293 & 50.3 \\
\hline & Yes & 290 & 49.7 \\
\hline \multicolumn{4}{|c|}{ Source of referral $(n=583)$} \\
\hline & $\mathrm{NCRH}$ & 47 & 8.1 \\
\hline & $\mathrm{CCRH}$ & 49 & 8.4 \\
\hline & SCRH & 47 & 8.1 \\
\hline & ECRH & 38 & 6.5 \\
\hline & Addis Ababa & 158 & 27.1 \\
\hline & Training center & 41 & 7.0 \\
\hline & Other -pension & 155 & 26.5 \\
\hline & Other -family & 35 & 6.0 \\
\hline & Other-other & 13 & 2.3 \\
\hline \multicolumn{4}{|l|}{ Smoking $(\mathrm{n}=583)$} \\
\hline & No & 519 & 89.0 \\
\hline & Yes & 64 & 11.0 \\
\hline \multicolumn{4}{|c|}{ Duration of smoking $(\mathrm{n}=64)$} \\
\hline & $<5$ years & 11 & 1.9 \\
\hline & $5-<10$ years & 13 & 2.2 \\
\hline & $>=10$ years & 40 & 6.9 \\
\hline
\end{tabular}

Three hundred thirty six $(56.5 \%)$ respondents do regular physical exercise of light, moderate and vigorous types in $131(22.5 \%), 172(29.5 \%), 33(5.7 \%)$, respectively. Four hundred forty three $(76 \%)$ respondents have tender point on lumbar palpation and 451 (77.4\%) have stress. Comorbidities are found in $290(49.7 \%)$. LBP duration is found more than or equal to 12 weeks in $389(66.7 \%)$ and in $111(19 \%)$ it is not applicable. BMI is less than $25 \mathrm{~kg} / \mathrm{m}^{2}$ in $349(59.9 \%)$ of respondents (Table 4).

Logistic regressions for bivariate and multivariable analysis of categorical and numerical variables were done for determinants of lower back pain to check for association with the dependent variable. To accommodate all possible associated factors, those with P-value less than or equal to 0.1 on bivariate logistic analysis were included in multivariable logistic model. Multicollinearity statistics was done and variance inflation factors for all the variables were less than 10. Hosmer and Lemeshow Test were done and Pvalue is 0.78 it is greater than 0.05 meaning the model is fit, and Nagelkerke $\mathrm{R}$ square of the model is 0.478 meaning $47.8 \%$ of the independent variables which predict LBP were included in the model for analysis.

On bivariate analysis age categories in years of 25-34, 35.44 and $45+$ showed significant association with COR $(95 \% \mathrm{CI})$
2.44 (1.02, 5.84), $3.72(1.60,8.63)$, and 7.54 (3.27, 17.41), respectively. Female gender also has significant association with LBP with COR $(95 \% \mathrm{CI})$ of $2.15(1.37,3.36)$ while that of pensioned military status is $1.69(1.15,2.48)$ in the bivariate analysis. Ten or more years of service, weakness experienced during presentation, numbness and tingling sensation have association with lower back pain with COR $(95 \% \mathrm{CI})$ of 2.68 (1.67, 4.31), 2.09 (1.39, 3.16) and 3.75 (2.57, 5.47), respectively. Moreover, COR $(95 \% \mathrm{CI})$ of that of tender point is $11.73(7.49,18.38)$, of past recommended spinal surgery is $4.74(2.68,8.39)$, of non -surgical pain management is 1.97 $(1.09,3.55)$, of previous LBP is $2.58(1.54,4.35)$, of lifting objects more than equal to $25 \mathrm{kgs}$ is $2.44(1.63,3.67)$ and of obesity is $1.66(1.16,2.38)$ (Tables $5 \& 6)$.

Bivariate analysis with COR $(95 \% \mathrm{CI})$ in range of 0 to 1 but having significant association includes smoking 0.59 $(0.35,0.99)$, comorbidities $0.56(0.39,0.79)$, accidental fall $0.60(0.42,0.86)$, moderate regular physical exercise 0.26 $(0.17,0.39)$, and vigorous regular physical exercise 0.24 $(0.12,0.52)$, Educational level, provision of office for working, sitting more than 6 hours a day, working more than 48 hours per week, stress, duration of LBP, and past performed spinal surgery showed no association with LBP on bivariate logistic regression analysis (Tables 5\&6). 
In multivariable logistic regression analysis only previous recommended spinal surgery, tender point, comorbidities, and numbness and tingling sensation have significant association with AOR $(95 \% \mathrm{CI})$ of $2.18(1.06,4.45), 4.36(2.17,8.77), 0.57$ $(0.35,0.95)$, and $2.92(1.71,4.96)$; respectively (Tables $5 \& 6)$.

Table 3. Clinical Characteristics of respondents among neurological and neurosurgical adult patients at Armed Force Comprehensive Specialized Hospital from December 16, 2017 to March 23, $2018(n=583)$.

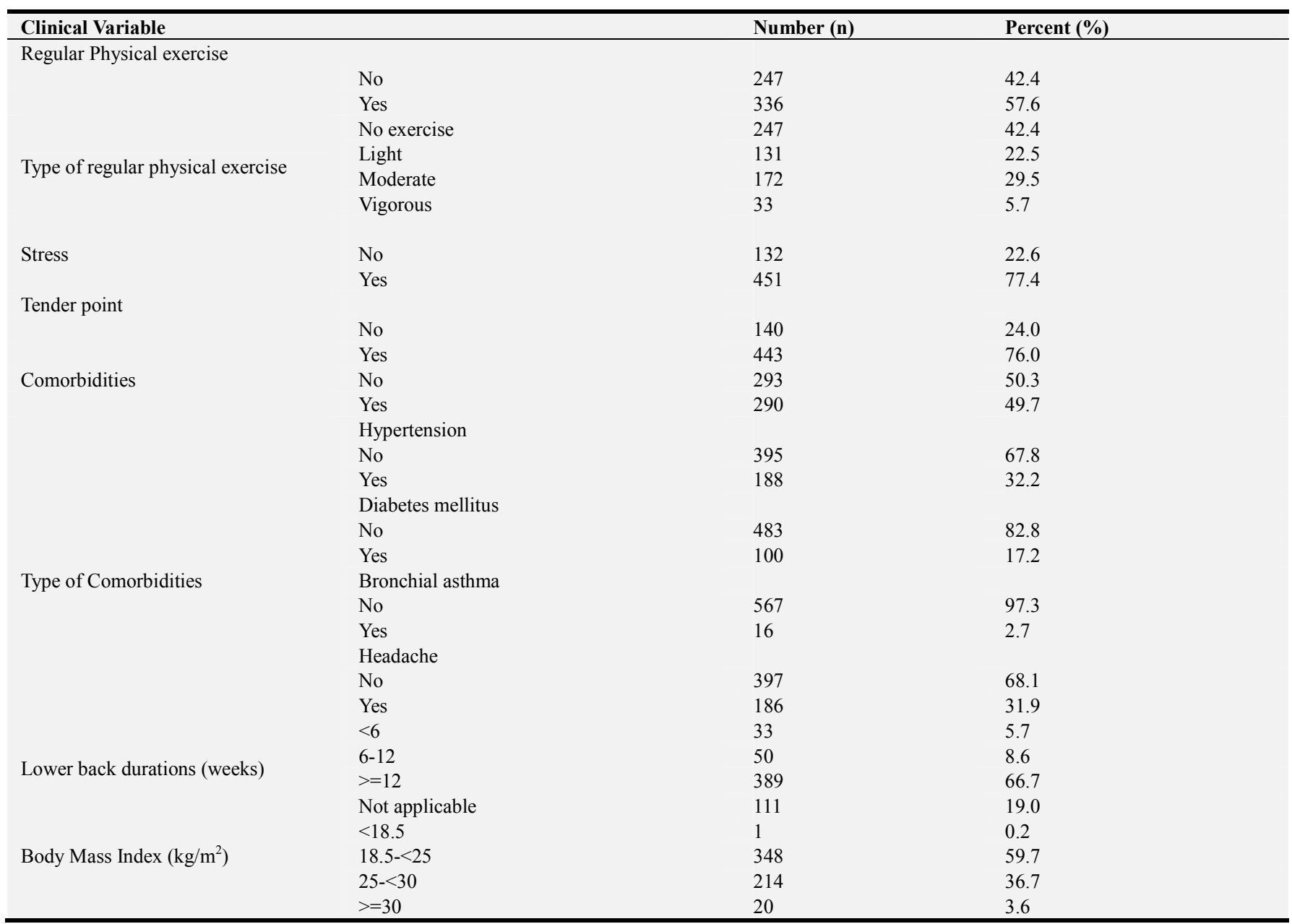

Table 4. Clinical Characteristics of respondents among neurological and neurosurgical adult patients at Armed Force Comprehensive Specialized Hospital from December 16, 2017 to March 23, $2018(n=583)$.

\begin{tabular}{|c|c|c|c|}
\hline Clinical Variable & & Number (n) & Percent (\%) \\
\hline \multicolumn{4}{|c|}{ Numbness and tingling sensation } \\
\hline & No & 168 & 28.8 \\
\hline & Yes & 415 & 71.2 \\
\hline \multicolumn{4}{|l|}{ Weakness of legs } \\
\hline & No & 418 & 71.7 \\
\hline & Yes & 165 & 28.3 \\
\hline \multicolumn{4}{|c|}{ Recommended spinal surgery } \\
\hline & Yes & 122 & 20.9 \\
\hline \multicolumn{4}{|c|}{ Spinal surgery performed } \\
\hline & No & 568 & 97.4 \\
\hline & Yes & 15 & 2.6 \\
\hline \multicolumn{4}{|l|}{ Past LBP } \\
\hline & No & 477 & 81.8 \\
\hline & Yes & 106 & 18.2 \\
\hline & Yes & 461 & 79.1 \\
\hline \multicolumn{4}{|l|}{ Accidental Fall } \\
\hline & No & 240 & 41.2 \\
\hline & Yes & 343 & 58.8 \\
\hline
\end{tabular}




\begin{tabular}{|c|c|c|c|}
\hline Clinical Variable & & Number (n) & Percent (\%) \\
\hline \multicolumn{4}{|l|}{ Non -surgical Treatments for LBP } \\
\hline & No & 49 & 8.4 \\
\hline & Yes & 534 & 91.6 \\
\hline \multicolumn{4}{|l|}{ Types of Non -surgical treatment taken } \\
\hline \multirow[t]{2}{*}{ NSAIDs } & No & 244 & 41.9 \\
\hline & Yes & 339 & 58.1 \\
\hline \multirow[t]{2}{*}{ Opiates (Tramadol) } & No & 428 & 73.4 \\
\hline & Yes & 155 & 26.6 \\
\hline \multirow[t]{2}{*}{ TCAs (Amitriptyline) } & No & 519 & 89.0 \\
\hline & Yes & 64 & 11.0 \\
\hline \multirow[t]{2}{*}{ AEDs (Carbamazepine) } & No & 542 & 93.0 \\
\hline & Yes & 41 & 7.0 \\
\hline \multirow[t]{2}{*}{ Paracetamol } & No & 558 & 95.7 \\
\hline & Yes & 25 & 4.3 \\
\hline \multirow[t]{2}{*}{ Physiotherapy } & No & 580 & 99.5 \\
\hline & Yes & 3 & 0.5 \\
\hline \multirow[t]{2}{*}{ Others (neurobin (2)+unspecified drugs) } & No & 561 & 96.2 \\
\hline & Yes & 22 & 3.8 \\
\hline
\end{tabular}

Table 5. Multivariable logistic regression for associated factors of lower back pain among neurological and neurosurgical adult patients at Armed Forces Comprehensive Specialized Hospital from December 16, 2017 to March 23, 2018.

\begin{tabular}{|c|c|c|c|c|c|}
\hline \multirow{2}{*}{ Variable } & & \multicolumn{2}{|c|}{ Lower back pain } & \multirow[t]{2}{*}{ COR $(95 \% \mathrm{CI})$} & \multirow[t]{2}{*}{ AOR (95\%CI) } \\
\hline & & Yes & No & & \\
\hline \multicolumn{6}{|l|}{ Age Category } \\
\hline & $18-24$ & 9 & 20 & 1 & 1 \\
\hline & $25-34$ & 56 & 51 & $2.44(1.02,5.84)$ & $1.47(0.43,5.05)$ \\
\hline & $35-44$ & 112 & 67 & $3.72(1.60,8.63)$ & $2.33(0.61,8.92)$ \\
\hline & $45+$ & 207 & 61 & $7.54(3.27,17.41)$ & $2.92(0.69,12.36)$ \\
\hline \multicolumn{6}{|c|}{+5} \\
\hline & Male & 278 & 169 & 1 & 1 \\
\hline & Female & 106 & 30 & $2.15(1.37,3.3)$ & $1.48(0.72,3.03)$ \\
\hline \multirow[t]{2}{*}{ Current military status } & Active & 218 & 135 & 1 & 1 \\
\hline & Pension & 139 & 51 & $1.69(1.15,2.48)$ & $1.49(0.70,3.16)$ \\
\hline \multicolumn{6}{|l|}{ Educational level } \\
\hline & Illiterate & 3 & 3 & 1 & 1 \\
\hline & Primary & 96 & 81 & $1.19(0.23,6.03)$ & $3.04(0.41,22.62)$ \\
\hline & Secondary & 170 & 70 & $2.43(0.48,12.33)$ & $4.48(0.59,34.18)$ \\
\hline & Tertiary & 115 & 45 & $2.56(0.50,13.14)$ & $3.38(0.41,27.71)$ \\
\hline \multirow{2}{*}{ Working office provided $* *$} & Yes & 171 & 80 & $1.19(0.84,1.69)$ & \\
\hline & No & 213 & 119 & 1 & \\
\hline \multirow{2}{*}{ Sitting more than 6hours $* *$} & Yes & 188 & 104 & $0.88(0.62,1.23)$ & \\
\hline & No & 196 & 95 & 1 & \\
\hline \multirow{2}{*}{ Working more than or equal to 48 hours** } & Yes & 184 & 106 & $0.81(0.57,1.14)$ & \\
\hline & No & 200 & 93 & 1 & \\
\hline \multicolumn{6}{|l|}{ Monthly Income category } \\
\hline & $<1750$ & 99 & 41 & 1 & 1 \\
\hline & $1750-3600$ & 132 & 104 & $0.53(0.33,0.82)$ & $0.79(0.37,1.69)$ \\
\hline & $3600-6500$ & 99 & 33 & $1.24(0.73,2.12)$ & $1.35(0.47,3.88)$ \\
\hline & $>6500$ & 20 & 8 & $1.04(0.42,2.54)$ & $1.21(0.31,4.63)$ \\
\hline \multicolumn{6}{|l|}{ Year of service } \\
\hline & $<10$ years & 38 & 45 & 1 & 1 \\
\hline & $>=10$ years & 317 & 140 & $2.68(1.67,4.31)$ & $0.59(0.25,1.39)$ \\
\hline \multirow[t]{2}{*}{ Smoking } & Yes & 35 & 29 & $0.59(0.35,0.99)$ & $0.51(0.24,1.07)$ \\
\hline & No & 349 & 170 & 1 & 1 \\
\hline \multirow[t]{2}{*}{ Numbness and tingling } & Yes & 310 & 105 & $3.75(2.57,5.47)$ & $2.92(1.71,4.96)$ \\
\hline & No & 74 & 94 & 1 & 1 \\
\hline
\end{tabular}

N. B. ** P-value $>0.1$ on bivariate logistic regression

Table 6. Multivariable logistic regression for determinants of lower back pain among neurological and neurosurgical adult patients at Armed Forces Comprehensive Specialized Hospital from December 16, 2017 to March 23, 2018.

\begin{tabular}{llllll}
\hline \multirow{2}{*}{ Variable } & & \multicolumn{2}{l}{ Lower back pain } & COR (95\%CI) & AOR (95\%CI) \\
\cline { 2 - 6 } & & Yes & No & & \\
\hline Weakness experienced & Yes & 127 & 38 & $2.09(1.39,3.16)$ & $0.715(0.39,1.30)$ \\
\multirow{2}{*}{ Tender point } & No & 257 & 161 & 1 & 1 \\
& Yes & 350 & 93 & $11.73(7.49,18.38)$ & $4.36(2.17,8.77)$ \\
\hline
\end{tabular}




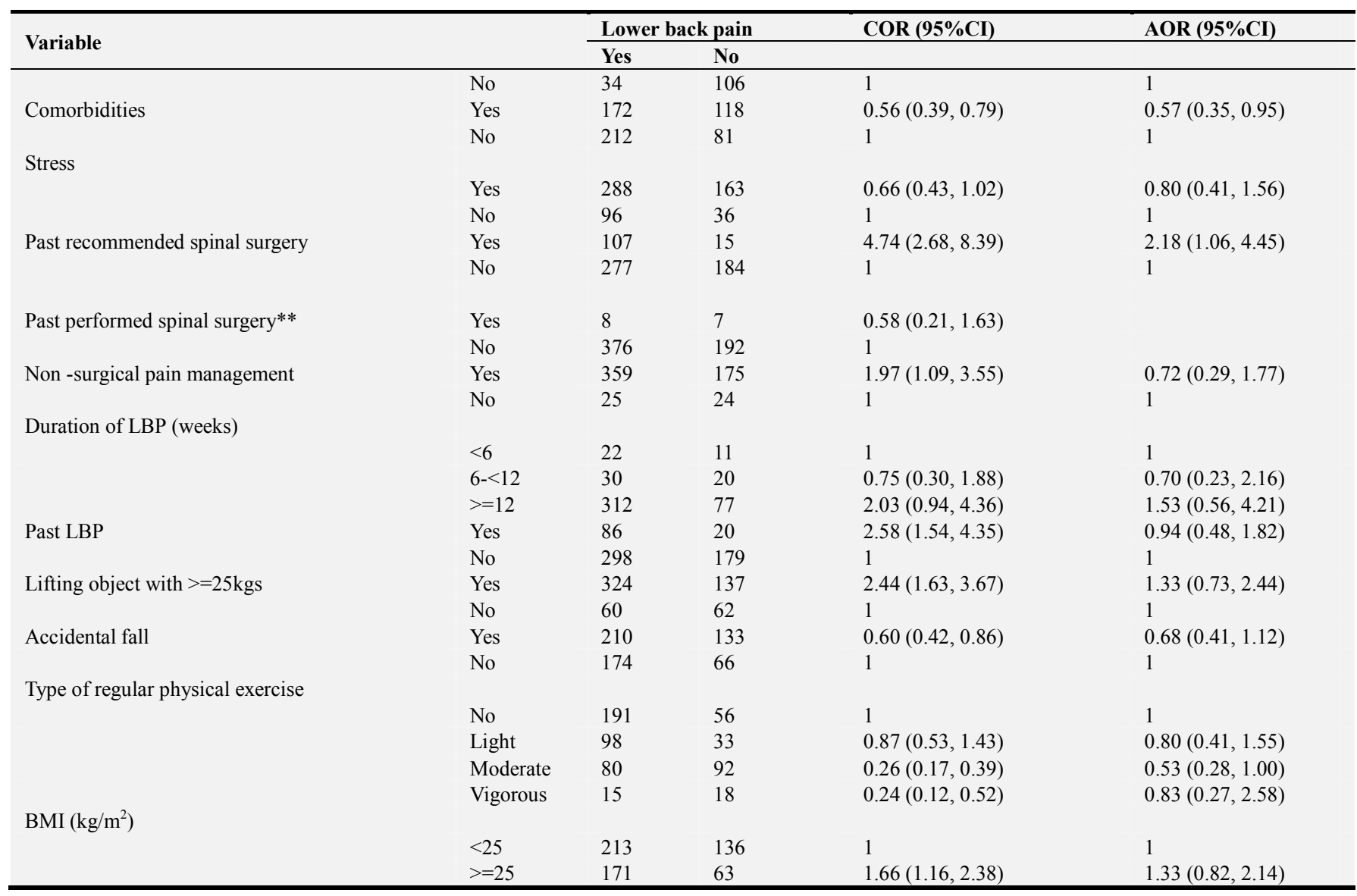

N. B. ** P-value $>0.1$ on bivariate logistic regression

\section{Discussion}

A cross sectional study with internal comparison was carried out to assess the magnitude of LBP and its determinants among neurological and neurosurgical adult patients at Armed Forces Comprehensive Specialized Hospital from December 16, 2017 to March 23, 2018. The response rate of the study was $99.7 \%$.

The magnitude of patients with LBP is $65.9 \%$ with $95 \%$ CI $(62.1,69.8)$ is high that is within range of that of a systematic review done in general populations and nurses of USA [45], but it is higher than what was seen in studies done other settings and different professions like Brazilian athletes [16], China farmers [6], Iranian workforces and job groups [31], and Saudi teachers [32]; different professionals in African countries including Zimbabwe, Botswana and Tunisia [3337]; and also Ethiopian Adama medical college staffs, Gonder teacher and nurses, back loading pedestrian women in Jimma and TAH nurses $[5,8,12,16,21]$. The apparent reason is that the study populations are neurological and neurosurgical patients.

On bivariate analysis age categories in years, female gender, pensioned military, more than or equal to 10 years of service, weakness experienced during presentation, numbness and tingling sensation, tender point, past recommended spinal surgery, non -surgical pain management, previous LBP, lifting objects more than equal to $25 \mathrm{kgs}$ and BMI showed significant association with LBP with COR greater than 1 and 95\% CI did not encompass 1 . Whereas bivariate logistic regression analysis also showed COR and $95 \% \mathrm{CI}$ in range of 0 to 1 with significant association with protective effects on LBP include smoking, comorbidities, accidental fall and moderate or vigorous regular physical exercise.

Female participants are more likely to have LBP as compared to male in studies of other settings and professions [4-7, 38]. Doing regular physical exercise has protective effect on LBP in different studies [12, 22-24]; doers had more likely of LBP than no exercise doers in a study done Ethiopian nurses [15], and has no association in Brazil athletes [16] but in this study it has protective effect on bivariate analysis but no association in multivariable logistic regression. Those participants with stress are more likely to have LBP in studies done Ethiopian nurses and Chinese Farmers that is different with this study $[6,15]$. Those with BMI $\left(\mathrm{kg} / \mathrm{m}^{2}\right)$ more than or equal to 25 are more likely to have LBP than BMI less than $25[9,19,21]$ but no association in study done in Ethiopian [8]. This could be due to association of BMI and LBP vary by country [20]. Ten or more years of services have adverse effect in studies done in Ethiopian back loading pedestrian women and Iranian athletes [3, 9] but insignificant in Ethiopian nurses [15].

Work load that is sitting more than or equal to 6 hours a day [7, 12]; working more than 48 hours per week [13, 24], 
and provision of no office in working environment [8] have associated with more likely to have LBP unlike in this study which showed no association. Past history of LBP and lifting more than or equal to $25 \mathrm{~kg}$ objects are associated with high risk of developing LBP [13]. Having weakness has positive effect on developing LBP $[7,15]$. Those participants with comorbidity like Bronchial asthma or Diabetes mellitus have more chance of developing LBP than their counterpart [39] this is different with this study as chronic medical illness has protective effect in developing LBP. Educational level has no association in this study that is in line with study in Denmark [19]. Heterogeneity at study level and/ or personal level could explain the difference in association of associated factors in different groups of professional at within or across nations [4].

In multivariable logistic regression analysis only previous recommended spinal surgery, tender point, comorbidities, and numbness and tingling sensation have significant association with AOR $(95 \% \mathrm{CI})$ of $2.18(1.06,4.45), 4.36$ (2.17, 8.77), $0.57(0.35,0.95)$, and $2.92(1.71,4.96)$; respectively. The odds of participants having LBP are 4.4 times more likely in those with tender point at lumbosacral vertebrae as compared to those with no tender point on lumbosacral vertebrae. Those respondents who had been recommended for spinal surgery have 2.2 times more chance to have LBP than those who had not been recommended for spinal surgery.

The chance of having LBP is 2.9 times more likely in participants with symptoms of numbness and tingling sensation as compared to those without numbness and tingling sensation. Forty three percent reduced chance of LBP in those participants with having comorbidities as compared to those without comorbidities.

Numbness and tingling sensation, and tender point are sensory symptoms and signs, respectively. These would increase tendency of the respondents to utilize health services more than those without the symptoms and signs. In addition, previous recommended spinal surgery signifies the severity of LBP and utilization of health service hence contribute to high magnitude of LBP. In $75.1 \%$ of the study population leg pain present that is higher than what is seen in study done in Denmark $38(43 \%)$. Leg pain or radiation meaning that is root compression and there is spinal canal stenosis in spinal images in $1 / 3$ of the respondents which signify severity of the LBP and needs physical therapy and / or neurosurgical intervention at most but performed spinal surgery was low (15 $(2.6 \%)$ ) which was not proportional to recommended spinal surgery122 (20.9\%).

Moreover, having comorbidities leads the respondents to seek health care and hence high chance to get diagnosed of LBP when they have complaints of LBP.

\section{Strength of the Study}

As it is crossectional study it is best for magnitude study and it is less expensive. Probability sampling was done \& response rate is almost $100 \%$ which reduce selection bias, and pre-test of questionnaire, and training and supervision of data collectors were done which minimize interviewer bias. Multivariable logistic regression was done which controlled confounding effects of different associated factors of LBP. Restriction of two variables done that also control confounders.

\section{Limitation of the Study}

It is subjected to bias like interviewer bias, recall bias, and selection bias. As it is crossectional study temporal relation could not be clear, and institutional study it is difficulty to delineate the denominator for prevalence study. There is underrepresentation of smokers that might lead to inconclusive effect of smoking on LBP in this study.

\section{Conclusion and Recommendation}

The magnitude of lower back pain is high in neurological and neurosurgical adult patients of AFCSH and its associated factors which are determinants of lower back pain are previous recommended spinal surgery, tender point, comorbidities, and numbness and tingling sensation. It is public health and clinical significance condition hence to reduce the prevalence and to make the patients with LBP return to work with proper management, promotive, preventive, curative and rehabilitative measures to be taken timely. These include:

1) Strengthen neurological \& neurosurgical health services

2) Enhance rehabilitative services like physical therapy

\section{Acknowledgements}

My sincere gratitude goes for my advisor Prof. Alemayehu Worku for his technical assistance starting form the proposal development to the final thesis work. Moreover, I would like to praise the Armed Forces Comprehensive Specialized Hospital for providing me stationaries and allowing the research to be carried out. My last but not least gratitude would be for study participant for their willingness to take part in the study, data collectors for data collection, my friend Dr. Tihitina Negusse Mamo for translating the questionnaire. I declare no conflict of interest.

\section{References}

[1] Allan H R, Robert H B. Adams \& Victors' Principles of Neurology, 8th Edition. 2005. 169-183 p.

[2] Global, regional, and national incidence, prevalence, and years lived with disability for 310 diseases and injuries, 1990-2015: a systematic analysis for the Global Burden of Disease Study 2015. Lancet Lond Engl. 2016 Oct 8; 388 (10053): 1545-602.

[3] Henok A, Bekele T. Prevalence of musculoskeletal pain and factors associated with kyphosis among pedestrian backloading women in selected towns of Bench Maji zone, Southwest Ethiopia. Ethiop J Health Dev EJHD [Internet]. 2017 Jun 22; $31 \quad$ (2). Available from: http://ejhd.org/index.php/ejhd/article/view/1222. 
[4] Coggon D, Ntani G, Palmer KT, Felli VE, Harari R, Barrero $\mathrm{LH}$, et al. Disabling musculoskeletal pain in working populations: Is it the job, the person, or the culture? Pain. 2013 Jun; 154 (6): 856-63.

[5] El-Sayed AM, Hadley C, Tessema F, Tegegn A, Cowan JA, Galea S. Back and neck pain and psychopathology in rural sub-Saharan Africa: Evidence from the Gilgel Gibe Growth and Development Study, Ethiopia. Spine. 2010 Mar 15; 35 (6): 684-9.

[6] Liu X, Wang L, Stallones L, Wheeler KK, Zhao W, Smith GA, et al. Back Pain among Farmers in A Northern Area of China. Spine. 2012 Mar 15; 37 (6): 508-14.

[7] Monica S. Identifying Episodes of Back Pain Using Medical Expenditures Panel Survey (MEPS) Data: Patient Experience, Use of Services, and Chronicity. J Manipulative Physiol Ther. 2010 Oct; 33 (8): 562-75.

[8] Zele MYM and YT. Low Back Pain and Associated Factors among Teachers in Gondar Town, North Gondar, Amhara Region, Ethiopia. Occup Med Health Aff [Internet]. 2013 Aug 10; 2013. Available from: https://www.omicsonline.org/peerreviewed/low-back-pain-and-associated-factors-amongteachers-in-gondar-town-north-gondar-amhara-regionethiopia-16508.html.

[9] Moradi V, Memari A-H, ShayestehFar M, Kordi R. Low Back Pain in Athletes Is Associated with General and Sport Specific Risk Factors: A Comprehensive Review of Longitudinal Studies. Rehabil Res Pract [Internet]. 2015 [cited 2017 Aug 11]; $2015 . \quad$ Available from: http://www.ncbi.nlm.nih.gov/pmc/articles/PMC4691487/.

[10] Sikiru L, Shmaila H. Prevalence and risk factors of low back pain among nurses in Africa: Nigerian and Ethiopian specialized hospitals survey study. East Afr J Public Health. 2009 Apr; 6 (1): 22-5.

[11] Stewart Williams J, Ng N, Peltzer K, Yawson A, Biritwum R, Maximova T, et al. Risk Factors and Disability Associated with Low Back Pain in Older Adults in Low- and MiddleIncome Countries. Results from the WHO Study on Global AGEing and Adult Health (SAGE). PLoS ONE [Internet]. 2015 Jun 4 [cited 2017 Aug 11]; 10 (6). Available from: http://www.ncbi.nlm.nih.gov/pmc/articles/PMC4456393/.

[12] Alem Deksisa Abebe, Ephrem Mamo Gebrehiwot, Seblewengel Lema, Tilaye Workineh Abebe. Prevalence of Low Back Pain and Associated Risk Factors Among Adama Hospital Medical College Staff, Ethiopia. Eur J Prev Med. 2015; 3 (6): 188-92.

[13] Kawaguchi M, Matsudaira K, Sawada T, Koga T, Ishizuka A, Isomura $\mathrm{T}$, et al. Assessment of potential risk factors for new onset disabling low back pain in Japanese workers: findings from the CUPID (cultural and psychosocial influences on disability) study. BMC Musculoskelet Disord [Internet]. 2017 Aug 2 [cited 2017 Aug 11]; 18. Available from: http://www.ncbi.nlm.nih.gov/pmc/articles/PMC5541662/.

[14] Fett D, Trompeter K, Platen P. Back pain in elite sports: A cross-sectional study on 1114 athletes. PLoS ONE [Internet]. 2017 Jun 29 [cited 2017 Aug 11]; 12 (6). Available from: http://www.ncbi.nlm.nih.gov/pmc/articles/PMC5491135/.

[15] Belay MM, Worku A, Gebrie SA, Wamisho BL. Epidemiology of Low Back Pain among Nurses Working in Public Hospitals of Addis Ababa, Ethiopia. COSECSAASEA Publ -East Cent Afr J Surg MarchApril 2016. Volume 21 (1).
[16] Noll M, de Avelar IS, Lehnen GC, Vieira MF. Back Pain Prevalence and Its Associated Factors in Brazilian Athletes from Public High Schools: A Cross-Sectional Study. PLoS ONE [Internet]. 2016 Mar 3 [cited 2017 Aug 11]; 11 (3). Available http://www.ncbi.nlm.nih.gov/pmc/articles/PMC4777545/.

[17] Dunn KM. Extending conceptual frameworks: life course epidemiology for the study of back pain. BMC Musculoskelet Disord. 2010 Feb 2; 11: 23.

[18] Wong AY, Karppinen J, Samartzis D. Low back pain in older adults: risk factors, management options and future directions. Scoliosis Spinal Disord [Internet]. 2017 Apr 18 [cited 2017 Aug 11]; $12 . \quad$ Available from: http://www.ncbi.nlm.nih.gov/pmc/articles/PMC5395891/.

[19] Brady SRE, Hussain SM, Brown WJ, Heritier S, Billah B, Wang Y, et al. Relationships Between Weight, Physical Activity, and Back Pain in Young Adult Women. Medicine (Baltimore) [Internet]. 2016 May 13 [cited 2017 Aug 11]; 95 (19). Available from: http://www.ncbi.nlm.nih.gov/pmc/articles/PMC4902476/.

[20] Koyanagi A, Stickley A, Garin N, Miret M, Ayuso-Mateos JL, Leonardi $\mathrm{M}$, et al. The association between obesity and back pain in nine countries: a cross-sectional study. BMC Public Health [Internet]. 2015 Feb 11 [cited 2017 Aug 11]; 15. Available from: http://www.ncbi.nlm.nih.gov/pmc/articles/PMC4331391/.

[21] Yitayeh A. Annual Prevalence of Self-Reported Work Related Musculoskeletal Disorders and Associated Factors among Nurses Working at Gondar Town Governmental Health Institutions, Northwest Ethiopia. Emerg Med Los Angel 2015 51. (1).

[22] Gordon R, Bloxham S. A Systematic Review of the Effects of Exercise and Physical Activity on Non-Specific Chronic Low Back Pain. Healthcare [Internet]. 2016 Apr 25 [cited 2017 Aug 11]; 4 (2). Available from: http://www.ncbi.nlm.nih.gov/pmc/articles/PMC4934575/.

[23] Budhrani-Shani P, Berry DL, Arcari P, Langevin H, Wayne PM. Mind-Body Exercises for Nurses with Chronic Low Back Pain: An Evidence-Based Review. Nurs Res Pract [Internet]. 2016 [cited 2017 Aug 11]; 2016. Available from: http://www.ncbi.nlm.nih.gov/pmc/articles/PMC4947504/.

[24] Chercos DH, Berhanu D. Work related injury among Saudi Star Agro Industry workers in Gambella region, Ethiopia; a crosssectional study. J Occup Med Toxicol Lond Engl [Internet]. 2017 Mar 16 [cited 2017 Aug 11]; 12. Available from: http://www.ncbi.nlm.nih.gov/pmc/articles/PMC5356299/.

[25] Misganaw A, Melaku YA, Tessema GA, Deribew A, Deribe K, Abera SF, et al. National disability-adjusted life years (DALYs) for 257 diseases and injuries in Ethiopia, 1990 2015: findings from the global burden of disease study 2015 . Popul Health Metr. 2017 Jul 21; 15: 28.

[26] Tadesse S, Bezabih K, Destaw B, Assefa Y. Awareness of occupational hazards and associated factors among welders in Lideta Sub-City, Addis Ababa, Ethiopia. J Occup Med Toxicol. 2016 Apr 5; 11: 15.

[27] Wainwright E, Wainwright D, Keogh E, Eccleston C. Return to work with chronic pain: employers' and employees' views. Occup Med. 2013 Oct 1; 63 (7): 501-6.

[28] Mark DV. LOWER BACK PAIN Questionnaire. 
[29] Casser H-R, Seddigh S, Rauschmann M. Acute Lumbar Back Pain. Dtsch Ärztebl Int. 2016 Apr; 113 (13): 223-34.

[30] Defining Adult Overweight and Obesity | Overweight \& Obesity $\mid$ CDC [Internet]. [cited 2017 Sep 20]. Available from: https://www.cdc.gov/obesity/adult/defining.html.

[31] Choobineh A, Daneshmandi H, Saraj Zadeh Fard SK, Tabatabaee SH. Prevalence of Work-related Musculoskeletal Symptoms among Iranian Workforce and Job Groups. Int J Prev Med [Internet]. 2016 Dec 15 [cited 2017 Aug 11]; 7. Available http://www.ncbi.nlm.nih.gov/pmc/articles/PMC5200977/.

[32] Abdulmonem A, Hanan A, Elaf A, Haneen T, Jenan A. The prevalence of musculoskeletal pain \& its associated factors among female Saudi school teachers. Pak J Med Sci. 2014; 30 (6): 1191-6.

[33] Chiwaridzo M, Naidoo N. Prevalence and associated characteristics of recurrent non-specific low back pain in Zimbabwean adolescents: a cross-sectional study. BMC Musculoskelet Disord [Internet]. 2014 Nov 19 [cited 2017 Aug 11]; 15. Available from: http://www.ncbi.nlm.nih.gov/pmc/articles/PMC4246475/.

[34] Morris L, Daniels K, Louw Q. The prevalence of low back pain in Africa. Man Ther. 2016 Sep 1; 25: e122-3.
[35] Louw QA, Morris LD, Grimmer-Somers K. The Prevalence of low back pain in Africa: a systematic review. BMC Musculoskelet Disord. 2007 Nov 1; 8: 105.

[36] Triki M, Koubaa A, Masmoudi L, Fellmann N, Tabka Z. Prevalence and risk factors of low back pain among undergraduate students of a sports and physical education institute in Tunisia. Libyan J Med [Internet]. 2015 Mar 9 [cited 2017 Aug 11]; 10. Available from: http://www.ncbi.nlm.nih.gov/pmc/articles/PMC4355506/.

[37] Erick PN, Smith DR. Low back pain among school teachers in Botswana, prevalence and risk factors. BMC Musculoskelet Disord [Internet]. 2014 Oct 30 [cited 2017 Aug 11]; 15. Available from: http://www.ncbi.nlm.nih.gov/pmc/articles/PMC4230345/.

[38] Coggon D, Ntani G, Palmer KT, Felli VE, Harari R, Barrero LH, et al. Patterns of multisite pain and associations with risk factors. Pain. 2013 Sep; 154 (9): 1769-77.

[39] Vancampfort D, Koyanagi A, Ward PB, Rosenbaum S, Schuch FB, Mugisha J, et al. Chronic physical conditions, multimorbidity and physical activity across 46 low- and middle-income countries. Int $J$ Behav Nutr Phys Act [Internet]. 2017 Jan 18 [cited 2017 Aug 11]; 14. Available from: http://www.ncbi.nlm.nih.gov/pmc/articles/PMC5241915/. 